\title{
Discussion: The National Library
}

\section{Nigel MacCartney}

There are elements of exaggeration in Derek Law's talk. Both Derek Law and David Russon have missed the fact that the British Library has contributed to a vital and thriving research community in Library and Information Science, which has set an international and global agenda.

There is a problem relating to research, and this has to do with who controls the research budget and agenda. The feeling in the library and information science community is that the British Library is known globally; but is it an appropriate body to hold the budget and control the agenda? What will the British Library do with the budget if no-one is watching? When it was proposed that the Library and Information Commission should take over this role, the British Library didn't oppose the change, but is there a worry that just another layer of bureaucracy is being added.

It is also worth noting that the role of the $\mathrm{R} \& \mathrm{D}$ departments within many large corporations is being downsized.

The British Library has been looking at its whole culture, and has introduced a change programme aimed to push all staff more towards an even higher level of service.

Research projects haven't always delivered what should have been done, but this is because the British Library has had to support smaller, more thinly spread projects, which has led to conflict with larger projects. There have also been artificial constraints due to funding.

\section{David Russon}

The whole issue of government funding is crucial.

Roger Bowes

I agree with Derek Law that the British Library is inward looking, and has distanced itself from the Library and Information Science community and from the international scientific community.

We wanted to find out what the scientific community themselves thought, so we decided to conduct a survey through Managing Information to see how inward looking the scientific community thought the British Library was. About 700 people were e-mailed, and 100 replies were received from the scientific community, saying how valuable the British Library is, which is a very optimistic outlook.

\section{David Russon}

Recent British Library consultation exercise had generated a very similar response. 